PACS: 12.20. - M; 31.15.AR; 31.25,-V; 31.30.JV; 32.10.FN

УДК 539.184

\title{
ESTIMATING OF X-RAY SPECTRA FOR KAONIC AND PIONIC ATOMS AS A TOOL FOR SENSING THE NUCLEAR STRUCTURE
}

\author{
O. Yu. Khetselius, A. V. Turin, D. E. Sukharev, T. A. Florko \\ I. I. Mechnikov Odessa National University, Odessa
ESTIMATING OF X-RAY SPECTRA FOR KAONIC AND PIONIC ATOMS AS TOOL FOR SENSING THE NUCLEAR STRUCTURE \\ O. Yu. Khetselius, A. V. Turin, D. E. Sukharev, T. A. Florko
}

\begin{abstract}
The levels energies and energy shifts are calculated for superheavy Li-like uranium and some kaonic and pionic atoms on the basis of the gauge-invariant QED perturbation theory (PT) with an account of nuclear, exchange-correlation and radiative effects. Estimating the spectra can be by a new tool for sensing the nuclear structure.
\end{abstract}

Keywords: QED perturbation theory, heavy ions, kaonic and pionic atoms

\section{ДОСЛІДЖЕННЯ РЕНТГЕНІВСЬКИХ СПЕКТРІВ КАОННИХ ТА ПІОННИХ АТОМІВ ЯК ЗАСІБ ДЛЯ ДЕТЕКТУВАННЯ ЯДЕРНОЇ СТРУКТУРИ}

\section{О. Ю. Хещеліус, О. В. Тюрін, Д. Є. Сухарев, Т. О. Флорко}

Анотація. На підставі КЕД теорії збурень з урахуванням ядерних, обмінно-кореляційних, релятивістських та радіаційних ефектів розраховані енергії рівнів та енергетичні зсуви для важкого Li-подібного урану, деяких каонних та піонних атомів. Оцінка шуканих спектрів $\epsilon$ одним із нових засобів детектування ядерної структури.

Ключові слова: КЕД теорія збурень, важкі іони, каонні та піонні атоми.

\section{ИССЛЕДОВАНИЕ РЕНТГЕНОВСКИХ СПЕКТРОВ КАОННЫХ И ПИОННЫХ АТОМОВ КАК СПОСОБ ДЕТЕКТИРОВАНИЯ ЯДЕРНОЙ СТРУКТУРЫ}

О. Ю. Хещелиус, А. В.Тюрин, Д. Е. Сухарев, Т. А. Флорко

Аннотация. На основе КЭД теории возмущений с учетом ядерных, обменно-корреляционных, релятивистских и радиационных эффектов рассчитаны энергии уровней и энергетические сдвиги для тяжелого Li-подобного урана, некоторых каонных и пионных атомов. Оценка искомых спектров является одним из новых подходов к детектированию ядерной структуры.

Ключевые слова: КЭД теория возмущений, тяжелые ионы, каонные и пионные атомы

\section{Introduction}

In last years studying the heavy elements (ions) and hadronic atomic systems is of a great interest for further development of atomic and nuclear theories as well as new tools for sensing the nuclear structure and fundamental interactions, including the Standard model [1-14]. The collaborators of the E570 experiment $[6,7]$ measured X-ray energy of a kaonic helium atom, which is an atom consisting of a kaon (a negatively charged heavy particle) and a helium nucleus. The kaonic helium X-rays were detected by large-area Silicon Drift Detectors, which 
readout system was developed by SMI (see $[3,4,9])$. The studies of the low-energy kaon-nuclear strong interaction with strangeness have been performed by measurements of the kaonic atom X-rays with atomic numbers $Z=1-92$ [1]. It is known that the shifts and widths due to the strong interaction can be systematically understood using phenomenological optical potential models. Nevertheless, one could mention a large discrepancy between the theories and experiments on the kaonic helium $2 \mathrm{p}$ state. A large repulsive shift (about $-40 \mathrm{eV}$ ) has been measured by three experimental groups in the 1970's and 80's, while a very small shift $(<1 \mathrm{eV})$ was obtained by the optical models calculated from the kaonic atom $X$-ray data with $Z>2$ [1-6]. This significant disagreement (a difference of over 5 standard deviations) between the experimental results and the theoretical calculations is known as the "kaonic helium puzzle". A possible large shift has been predicted using the model assuming the existence of the deeply bound kaonic nuclear states. However, even using this model, the large shift of $40 \mathrm{eV}$ measured in the experiments cannot be explained. A remeasurement of the shift of the kaonic helium Xrays is one of the top priorities in the experimental research activities. In the theory of the kaonic and pionic atoms there is an important task, connected with a direct calculation of the radiative transition energies within consistent relativistic quantum mechanical and QED methods. The multi-configuration Dirac-Fock (MCDF) approximation is the most reliable approarch for multi-electron systems with a large nuclear charge; in this approarch oneand two-particle relativistic effects are taken into account practically precisely. The next important step is an adequate inclusion of QED corrections. This topic has been a subject of intensive theoretical and experimental interest (see [12-23]). In the present paper an effective ab initio approach to relativistic calculation of the spectra for multi-electron, heavy ions with an account of the relativistic, correlation, nuclear, radiative effects is used in the relativistic quantum calculation of the heavy multicharged uranium ion and some hadronic atomic systems. The level energies and energy shifts for these systems are estimated and in whole an analysis of the received data can be considered as a new tool for sensing the nuclear structure. Our calculation scheme is based on gauge-invariant QED perturbation theory (PT) [24-32] with an accurate account of the nuclear, exchange-correlation and radiative effects and generalized relativistic dynamical effec- tive field nuclear model using the optimized onequasiparticle representation in the theory of the relativistic systems [24,28]. All correlation corrections of the second order and dominated classes of the higher orders diagrams (electrons screening, particle-hole interaction, mass operator iterations) have been taken into account [24,28,31-33]. The magnetic inter-electron interaction is considered in the lowest approximation (in $\alpha^{2}$ parameter), the Lamb shift (LS) polarization part is described in the Uehling-Serber approximation, the self-energy part of the LS is considered effectively within the advanced Ivanov-Ivanova non-perturbative procedure [24].

\section{QED perturbation theory}

Let us describe the key moments of our approach to relativistic calculation of the spectra for multi-electron superheavy ions with an account of relativistic, correlation, nuclear, radiative effects (more details can be found in refs. [24-35]). Oneparticle wave functions for Li-like heavy ions are found from solution of the relativistic Dirac equation with potential, which includes the self-consistent potential, electric, polarization potentials of nucleus (see below). The wave functions of the zeroth approximation for kaonic and pionic atoms are found from the Klein-Gordon equation (kaonic atoms) [12,13]. To describe the nuclear finite size effect the smooth Gaussian function of the charge distribution in a nucleus is used. With regard to normalization we have:

$$
\rho(r \mid R)=\left(4 \gamma^{3 / 2} / \sqrt{\pi}\right) \exp \left(-\gamma r^{2}\right),
$$

where $\gamma=4 / \pi R^{2}, \quad R$ is the effective nucleus radius. The Coulomb potential for the spherically symmetric density $\rho(r)$ is:

$$
V_{\text {nucl }}(r \mid R)=-\left((1 / r) \int^{r} d r^{\prime} r^{\prime 2} \rho\left(r^{\prime} \mid R\right)+\int^{\infty} d r^{\prime} r^{\prime} \rho\left(r^{\prime} \mid R\right) .\right.
$$

It is determined by the following system of differential equations:

$$
\begin{gathered}
V^{\prime} n u c l(r, R)=\left(1 / r^{2}\right) \int_{0}^{r} d r^{\prime} r^{2} \rho\left(r^{\prime}, R\right) \equiv\left(1 / r^{2}\right) y(r, R) \\
y^{\prime}(r, R)=r^{2} \rho(r, R) \\
\rho^{\prime}(r, R)=-8 \gamma^{5 / 2} r / \sqrt{\pi} \exp \left(-\gamma r^{2}\right)= \\
=-2 \gamma r \rho(r, R)=-\frac{8 r}{\pi r^{2}} \rho(r, R)
\end{gathered}
$$

with the corresponding boundary conditions. Consider the Li-like ion as an example. One can write 
further the Dirac-Fock type equations for a threeelectron system $1 s^{2} n l j$. Formally they fall into oneelectron DF equations for orbitals $1 s, n l j$ with potential:

$$
V(r)=2 V(r j 1 s)+V(r j n l j)+V e x+V(r j R) .
$$

The part Vex accounts for exchange interelectron interaction. The core electron density is defined within gauge invariant QED approach $[24,28]$. All correlation corrections of the PT second and high orders (electrons screening, particlehole interaction etc.) are accounted for. Procedure for an account of the radiative QED corrections is given in detail in refs. [20,21,28,30,31]. Regarding the vacuum polarization effect let us note that this effect is usually taken into account in the first PT order by means of the Uehling potential: ]

$$
\begin{gathered}
U(r)=-\frac{2 \alpha}{3 \pi r} \int_{1}^{\infty} d t \exp (-2 r t / \alpha Z)\left(1+1 / 2 t^{2}\right) \frac{\sqrt{t^{2}-1}}{t^{2}} \equiv \\
\equiv-\frac{2 \alpha}{3 \pi r} C(g),
\end{gathered}
$$

where $g=\frac{r}{\alpha Z}$. In our calculation we usually use more exact approach. The Uehling potential, determined as a quadrature (6), may be approximated with high precision by a simple analytical function. The use of new approximation of the Uehling potential [30] permits one to decrease the calculation errors for this term down to $0.5-1 \%$. Besides, using such a simple analytical function form for approximating the Uehling potential allows its easy inclusion into the general system of differential equations.

A method for calculation of the self-energy part of the Lamb shift is based on an idea by IvanovIvanova $[20,21]$. In an atomic system the radiative shift and the relativistic part of the energy are, in. principle, determined by one and the same physical field. It may be supposed that there exists some universal function that connects the self -energy correction and the relativistic energy. The self-energy correction for the states of a hydrogen-like ion was presented by Mohr $[15,16]$ as:

$$
E_{S E}(H \mid Z, n l j)=0.027148 \frac{Z^{4}}{n^{3}} F(H \mid Z, n l j) .
$$

This result is modified for the states $1 s^{2} \mathrm{nlj}$ of Li-like ions. It is supposed that for any ion with $n l j$ electron over the core of closed shells this value may be presented as:

$$
E_{S E}(Z, n l j)=0.027148 \frac{\xi^{4}}{n^{3}} f(\xi, n l j)\left(\mathrm{cm}^{-1}\right) .
$$

The parameter $\xi=\left(E_{R}\right)^{1 / 4}, E_{R}$ is the relativistic part of the outer electron bounding energy; the universal function $f(\xi, n l j)$ does not depend on the composition of the closed shells and nuclear potential. The scheme of generalization for the case of Li-like ions with the finite nucleus consists of several steps (see details in refs. [20,21,30,31]). The procedure of generalization for a case of $\mathrm{Li}$ like ions with the finite nucleus consists of the following steps: 1). Calculation of the values $E_{R}$ and $\xi$ for the states $n l j$ of $\mathrm{H}$-like ions with the point nucleus (in accordance with the Zommerfeld formula); 2). Construction of an approximating function $f(\xi, n l j)$ by the found reference $Z$ and the appropriate $F(H \mid Z, n l j) ; 3)$. Calculation of $E_{R}$ and $\xi$ for the states $n l j$ of $L i$-like ions with the finite nucleus; 4). Calculation of $E_{S E}$ for the sought states by the formula (8). The energies of the states of $\mathrm{Li}$ like ions were calculated twice: with a conventional constant of the fine structure $\alpha=1 / 137.04$ and with $\tilde{\alpha}=\alpha / 1000$. The results of latter calculations were considered as non-relativistic. This permitted isolation of $E_{R}$ and $\xi$. A detailed evaluation of their accuracy may be made only after a complete calculation of $E_{S E}^{n}(L i Z, n l j)$. It may be stated that the above extrapolation method is more justified than using the widely spread expansions by the parameter $\alpha Z$. For all calculations the PC package "Superatom-ISAN" is used.

\section{Results and conclusions}

We carried out the calculation of spectra of nlj $(n=2-4)$ states for Li-like heavy ions with $\mathrm{Z}=20$ 100 , energies of circular $(n, l=n-1), 2<n<13$, transitions for kaonic atoms using the current world average kaon mass. In table 1 we present the calculation data for energies of $2 s_{1 / 2}-2 p_{1 / 2}$ transition in spectrum of $\mathrm{U}^{89+}$ ion, obtained by different methods (see refs. [16-21,26-28]): this work (column G), MCDF (A), model PT with the DF "0"approximation (B); relativistic PT with " 0 " Hartree-Fock potential (C); multiparticle PT with DF "0" approximation (D), the QED PT with optimized zeroth approximation. Agreement between all data and experiment is quite good, but more exact results are in the columns $\mathrm{C}$, F, G.

In figure 1 we present the experimental kaonic Helium-4 X-ray energy spectra. It is very important to note that the kaonic helium $3 \mathrm{~d}-2 \mathrm{p}, 4 \mathrm{~d}-2 \mathrm{p}, 5 \mathrm{~d}-2 \mathrm{p}$ transitions are clearly observed. 
Contributions to energy $(\mathrm{eV})$ of $2 \mathrm{~s}_{1 / 2}-2 \mathrm{p}_{1 / 2}$ transition for $\mathrm{U}^{89+}$ ion $(\mathrm{RC}-$ nucleus recoil correction $=0,1 \mathrm{eV}$; experiment: 280,59)

\begin{tabular}{|c|c|c|c|c|c|c|}
\hline Values & A & B & C & D & F & G \\
\hline Relativistic PT & 324,10 & 319,67 & 322,31 & 322,41 & 322,33 & 322,35 \\
\hline SE & $-56,08$ & $-52,09$ & $-54,34$ & $-54,24$ & $-54,16$ & $-54,18$ \\
\hline VP & 14,61 & 13,08 & 12,56 & 12,56 & 12,35 & 12,33 \\
\hline Full energy & 282,63 & 280,66 & 280,63 & 280,83 & 280,62 & 280,60 \\
\hline
\end{tabular}

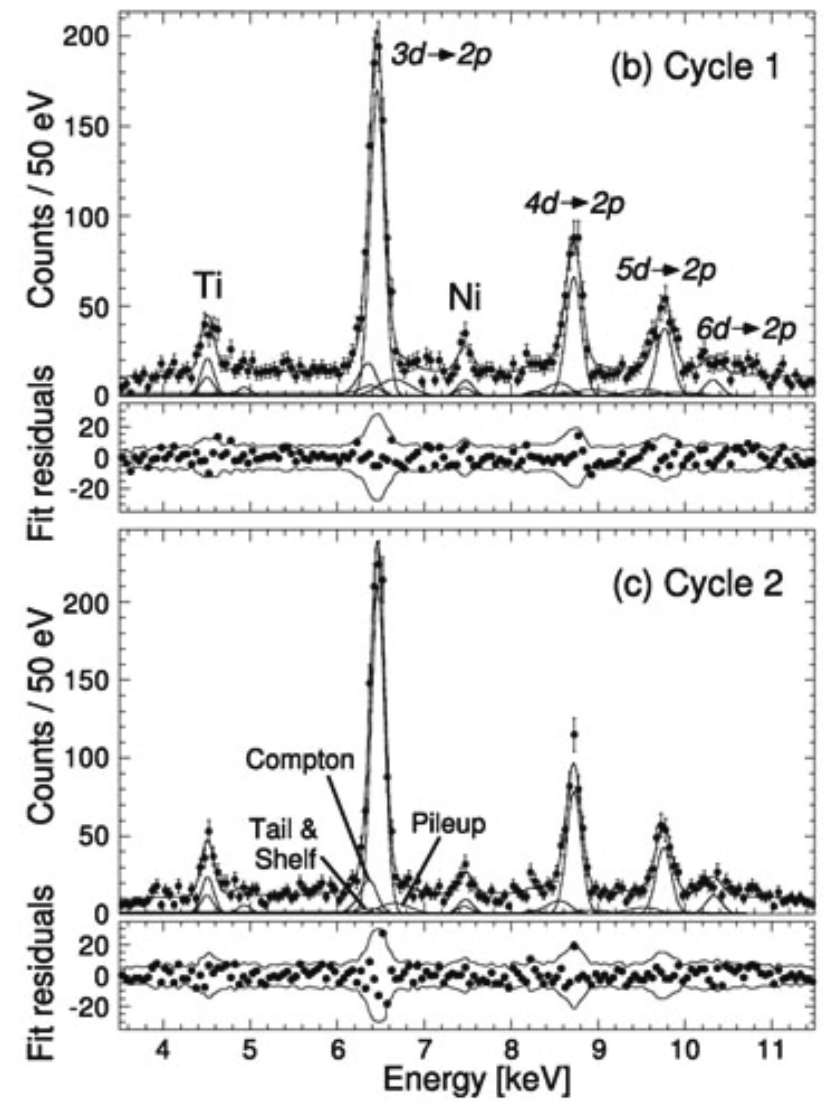

Fig.1. The experimental kaonic Helium-4 X-ray energy spectra. The kaonic helium $3 \mathrm{~d}-2 \mathrm{p}, 4 \mathrm{~d}-2 \mathrm{p}, 5 \mathrm{~d}-2 \mathrm{p}$ transitions are clearly observed (from refs. [6,7]).
The energy spectra of the kaonic helium X-rays are shown in the figure, and the measured energy of the kaonic helium X-ray lines are given in the table 2. The comparison with the previous experimental results is also shown. The 3 times higher statistics of the kaonic events, twice better energy resolution, and 6 times higher signal-to-background ratio were obtained. The obtained shift on the kaonic helium $2 p$ state is $2 \pm 2$ (stat) \pm 2 (sys) eV. This shift is consistent with the theoretically calculated values by both the optical potential models $(\sim 0 \mathrm{eV})$ and the model predicting the deeply bound kaonic states $(< \pm 10 \mathrm{eV})$, while it disagrees with the values in the past experiments. So, one can conclude here that the long-standing problem about the energy level of the $2 p$ state of the kaonic helium-4 was solved [6,7]. To understand further information on the low-energy kaon-nuclear interaction, new experiments to determine the shift and width of kaonic helium-3 and of kaonic hydrogen/deuterium are now in preparation in J-Parc and in LNF, respectively (look, for example, refs. [1,2,6]).

In table 2 we present the measured and calculated kaonic ${ }^{4} \mathrm{He} x$-ray energies $(\mathrm{eV})$ of $3 \mathrm{~d}-2 \mathrm{p}, 4 \mathrm{~d}-2 \mathrm{p}$ and $5 \mathrm{~d}-2 \mathrm{p}$ transitions. The transitions are identified by the initial $\left(n_{i}\right)$ and final $\left(n_{f}\right)$ quantum numbers. The calculated values of transition energies are compared with available measured $\left(\mathrm{E}_{\mathrm{m}}\right)$ and other calculated $\left(\mathrm{E}_{\mathrm{c}}\right)$ values $[1-4,13]$.

Table 2

Measured and calculated kaonic ${ }^{4} \mathrm{He} x$-ray energies $(\mathrm{eV})$ of $3 \mathrm{~d}-2 \mathrm{p}, 4 \mathrm{~d}-2 \mathrm{p}$ and $5 \mathrm{~d}-2 \mathrm{p}$ transitions

\begin{tabular}{|c|c|c|c|}
\hline Transition & $3 \mathrm{~d}-2 \mathrm{p}$ & $4 \mathrm{~d}-2 \mathrm{p}$ & $5 \mathrm{~d}-2 \mathrm{p}$ \\
\hline Experiment $[3,4]$ & $6466,7 \pm 2,5$ & $8723,3 \pm 4,6$ & $9760,1 \pm 7,7$ \\
\hline Theory $[2,7]$ & 6463,5 & 8721,7 & 9766,8 \\
\hline Present paper & 6468,03 & 8727,10 & 9767,54 \\
\hline
\end{tabular}

In table 3 we present the calculated X-ray energies of kaonic $\mathrm{H}$ and $\mathrm{U}$ atoms for transitions between circular levels. The majority of our transition energies are inside the experimental error bar. But, there is an exception, in particular, the 8-7 transition in U. In a case of good agreement between theoretical and experimental data, the corresponding levels are less sensitive to strong nuclear interaction. In the opposite case one could point to a strong-interaction effect in the exception cited above.

The pionic $6 \mathrm{~h}-5 \mathrm{~g}$ transition energies are calculated in the two pionic atoms: $\pi-^{22} \mathrm{Ne}$ and $\pi{ }^{20} \mathrm{Ne}$. The indicated energies can be calculated with high precision since the strong interaction plays no role 
for such high-lying circular states. We used the world average pion mass $\mathrm{m}=139.57018 \pm 0.00035 \mathrm{MeV}$ as given by the particle data group and fundamental constants (see refs. [3-5]). Here the Klein-Gordon equation for a spherical nuclear charge distribution is solved too. We obtained $4509.958 \mathrm{eV}$ and 4513.012
eV for the $6 \mathrm{~h}-5 \mathrm{~g}$ transition in ${ }^{22} \mathrm{Ne}$ and ${ }^{20} \mathrm{Ne}$, respectively. For comparison let us present the similar data by Indelicato et al [2]: $4509.894 \mathrm{eV}$ and 4512.948 $\mathrm{eV}$ respectively. The detailed analysis of the pionic atom transitions for other systems is presented in the paper [12].

Calculated $\left(\mathrm{E}_{\mathrm{c}}\right)$ and measured $\left(\mathrm{E}_{\mathrm{m}}\right)$ kaonic $\mathrm{H}$ and $\mathrm{U}$ atoms $\mathrm{X}$-ray energies (in $\mathrm{keV}$ )

Table 3

\begin{tabular}{|c|c|c|c|c|c|}
\hline Nucl. & Transition & $\mathrm{E}_{c}$, this work & $\mathrm{E}_{c}[6]$ & $\mathrm{E}_{c}[7]$ & $\mathrm{E}_{\mathrm{m}}$ \\
\hline $\mathrm{H}$ & $2-1$ & 6.650 & 6.481 & 6.480 & $6.675(60)$ \\
& & & & 6,482 & $6,96(9)$ \\
\hline $\mathrm{U}$ & $8-7$ & 538.328 & 538.013 & 537.44 & $538.315(100)$ \\
& & & & 538.72 & \\
\hline
\end{tabular}

\section{References}

1. Deloff A., Fundamentals in Hadronic Atom Theory, Singapore: World Scientific, 2003. - 352 p.

2. Hayano R.S., Hori M., Horvath D., Widman E., Antiprotonic helium and CPT invariance//Rep. Prog. Phys. - 2007. - Vol.70. - p. 1995-2065.

3. Deslattes R., Kessler E., Indelicato P., de Billy L., Lindroth E. , Anton J., Exotic atoms//Rev. Mod. Phys. - 2003. - Vol.75. - p. 35-70.

4. Trassinelli M., Indelicato P., Relativistic calculations of pionic and kaonic atoms hyperfine structure// arXiv:physics/0611263v2 [physics.atom-ph], 2007.

5. Anagnostopoulos D.F., Gotta D., Indelicato P., Simons L.M., Low-energy X-ray standards from hydrogenlike pionic atoms// arXiv:physics/0312090v1 [physics.atom-ph], 2003.

6. Okada S., Beer G., Bhang H., et al, Precision measurement of the $3 \mathrm{~d} \rightarrow 2 \mathrm{p} x$-ray energy in kaonic ${ }^{4} \mathrm{He} / /$ Phys.Lett.B. - 2007. - Vol.653, N 5-6. - P. 387391.

7. Okada S., Beer G., Bhang H., et al, Precision spectroscopy of Kaonic Helium 3d $\rightarrow$ 2p X-rays //Nucl. Phys.A. - 2007. - Vol.790,N1-4. - P.663-666.

8. Ito T.M., Hayano R.S., Nakamura S.N., Terada T.P., Observation of kaonic hydrogen atom $\mathrm{x}$ rays// Phys. Rev. C. - 1998. - Vol.58. - P.2366 - 2382.

9. Ishiwatari T. on behalf of the SIDDHARTA Collaboration, Silicon drift detectors for the kaonic atom Xray measurements in the SIDDHARTA experiment// Nucl.Instr. and Methods in Physics. Research Sec.A. Accelerators, Spectrometers, Detectors and Associated Equipment. - 2007. - Vol.581,N1-2. - P.326329.

10. Glushkov A.V., Makarov I.T., Nikiforova E.S., Pravdin M.I., Sleptsov I.Ye., Muon component of EAS with energies above $10^{17} \mathrm{eV} / /$ Astroparticle Physics. - 1995. - Vol.4, N1. - P. 15-22.

11. Glushkov A.V.,Dedenko L.G.,Pravdin M.I.,Sleptsov I.E., Spatio-temporal structure of the muon disk at $\mathrm{E}_{0}$ $\geq 5410^{16} \mathrm{eV}$ from EAS array data//JETP. - 2004. Vol.99,N1. - P.123-132.

12. Glushkov A.V., Khetselius O.Yu., Gurnitskaya E.P., Loboda A.V., Sukharev D.E., Relativistic Quantum Chemistry of Heavy Ions and Hadronic Atomic Systems: Spectra and Energy Shifts// Theory and Applications of Computational Chemistry (AIP). 2009. - Vol.1. - P.131-134.

13. Santos J.P., Parente F., Boucard S., Indelicato P., Desclaux j.P., X-ray energies of circular transitions and electron scattering in kaonic atoms//Phys. Rev A. - 2005. - Vol.71. - P.032501.

14. Karshenboim S.G., Kolachevsky N.N., Ivanov V.G., Fischer M., Fendel P., Honsch T.W., 2s-Hyperfine Splitting in Light Hydrogen-like Atoms: Theory and Experiment// JETP. - 2006. - Vol.102,N3. P.367-376.

15. Mohr P.J. Quantum Electrodynamics Calculations in few-Electron Systems// Phys. Scripta. - 1993. Vol.46,N1. - P.44-52.

16. Mohr P.J. Energy Levels of H-like atoms predicted by Quantum Electrodyna-mics, $10<\mathrm{Z}<40$ // Atom.Data Nucl .Data Tabl. - 1983-Vol.24,N2. - P.453-470.

17. Grant I., Relativistic Quantum Theory of Atoms and Molecules Theory and Computation, Springer Series on Atomic, Optical, and Plasma Physics. 200. Vol.40. - P.587-626.

18. Quiney H.M., Grant I.P. Partial-wave mass renormalization in atomic QED calculation // Phys.Scripta T. - 1993. - Vol.46. - P.132-138.

19. Wilson S., Recent Advances in Theoretical Physics and Chemistry Systems//Recent Advances in Theor. Phys. and Chem. Systems (Springer). - 2006. Vol.15. - P.11-45.

20. Ivanova E.P., Ivanov L.N., Aglitsky E.V., Modern Trends in Spectroscopy of multi-charged Ions// Physics Rep. - 1988. - Vol.166,N6. - P.315-390.

21. Ivanova E.P., Ivanov L.N., Glushkov A.V., Kramida A.E. High order corrections in the Relativistic Perturbation Theory with the model Zeroth Approxi- 
mation, Mg-like and Ne-like ions //Phys.Scripta 1985. - Vol.32,N4. - P.512-524.

22. Glushkov A.V., Energy Approach to Resonance states of compound super-heavy nucleus and EPPP in heavy nucleus collisions// Low Energy Antiproton Phys. (AIP). - 2005. - Vol.796. - P.206-210.

23. Glushkov A.V., Rusov V.D., Ambrosov S.V., Loboda A.V., Resonance states of compound super-heavy nucleus and EPPP in heavy nucleus collisions // New Projects and New Lines of research in Nuclear physics.Eds. Fazio G. and Hanappe F.: Singapore, World Sci. - 2003. - P. 142-154.

24. Glushkov A.V., Relativistic quantum theory. Quantum mechanics of atomic systems, Odessa: Astroprint, 2008. - $900 \mathrm{p}$.

25. Khetselius O.Yu., Hyperfine structure of atomic spectra, Odessa: Astroprint, 2008. - 210 p.

26. Glushkov A.V., Ambrosov S.V., Khetselius O.Yu., Loboda A.V., Gurnitskaya E.P., QED calculation of heavy multicharged ions with account for the correlation, radiative and nuclear effects// Recent Advances in Theory of Phys. and Chem. Systems (Springer). 2006. - Vol.15. - P.285-300.

27. Glushkov A.V., Khetselius O.Yu., Lovett L., et al, Gauge-invariant QED perturbation theory approach to calculating nuclear electric quadrupole moments, hyperfine structure constants for heavy atoms and ions// Frontiers in Quantum Systems in Chemistry and Physics (Springer). - 2008. - Vol.18. - P.505522.

28. Glushkov A.V., Ivanov L.N. Radiation Decay of Atomic States: atomic residue and gauge non-invariant contributions // Phys. Lett.A. - 1992. Vol.170(1). - P.33-38.

29. Glushkov A.V.,Malinovskaya S., Chernyakova Y.,Svinarenko A., Cooperative Laser- Electron-Nu- clear Processes: QED Calculation of Electron Satellites Spectra for Multicharged Ion in Laser Field// Int.Journ.Quant.Chem. - 2004. - Vol.99. - P.889898.

30. Glushkov A.V., Ambrosov S.V., Khetselius O.Yu., Loboda A.V., Chernyakova Y.G., Svinarenko A.A., QED calculation of the superheavy elements ions: energy levels, radiative corrections and hfs for different nuclear models// Nucl. Phys.A.: Nucl. and Hadr. Phys. - 2004. - Vol.734. - P. 21-24.

31. Glushkov A.V., Gurnitskaya E.P., Khetselius O.Yu., Energy levels, Lamb shift, hyperfine structure of heavy Li-like ions within QED calculation approach//Вісник Київського ун-ту. Сер фіз-.мат. 2004. - №4 . - C.421-426.

32. Glushkov A.V., Ambrosov S.V., Loboda A.V., Gurnitskaya E.P., Prepelitsa G.P., New QED approach to calculation of electron-collision excitation cross-sections and strengths: Ne-like ions // Int. Journ.Quant. Chem. - 2005. - Vol.104, N4 . - P. 562-569.

33. Glushkov A.V., Malinovskaya S.V., Dubrovskaya Yu.V., Vitavetskaya L.A., Quantum calculation of cooperative muon-nuclear processes: discharge of metastable nuclei during negative muon capture// Recent Advances in Theory of Phys. and Chem. Systems (Springer). - 2006. - Vol.15. - P.301-318.

34. Glushkov A.V., Khetselius O.Yu., Malinovskaya S.V., Spectroscopy of cooperative laser-electron nuclear effects in multiatomic molecules// Molec. Physics (UK). - 2008. - Vol.106. - N9\&10. - P.12571260.

35. Glushkov A.V., Khetselius O.Yu., Malinovskaya S.V., Optics and spectroscopy of cooperative laser-electron nuclear processes in atomic and molecular systems - new trend in quantum optics// Europ.Phys. Journ.ST. - 2008. - Vol.160,N1. - P.195-204. 